needs to read some of it. ${ }^{5}$

The first author of this response is also privileged to work in the real world as a GP. but this does not bring childish legitimacy to either his or Dr Fitzpatrick's opinions. If Dr Fitzpatrick's beliefs hang on his semantic understanding and interpretation of words, then he would do well to use the words exercise (structured activities) and physical activity (any bodily movement) appropriately. Sustained increases in physical activity and reductions in sedentary behaviour (in other words, time spent sitting or moving very little) are the behaviour changes that can be influenced with our patients and save much suffering and healthcare resource consumption. Such advice can only be effective when healthcare professionals are better educated in the benefits of physical activity and trained to deliver simple behaviour change techniques. To respond to his points:

1. It is quite possible that today's older population results from active lives commenced before technological advances and poor diets became habitual, and have lived alongside better health care. Levels of obesity, diabetes, numerous other diseases of inactivity, and poor lifestyles, once only seen in adults, are on a rapid rise in children. Perhaps Dr Fitzpatrick would do better to second guess the health of his patients when today's inactive children have grown up.

2. Dr Fitzpatrick's interpretation of the current physical activity recommendations is flawed: current guidance supports at least 150 minutes (for adults) of moderate intensity physical activity a week (not a minimum of 30 minutes on 5 days) broken up to a patients choosing, to gain minimum health benefits. ${ }^{6}$ Equivalent health benefits can be achieved with 75 minutes of more vigorous exercise a week, such as running or playing football. We are unsure how it is possible for a club runner or committed footballer to do less than the equivalent of 75 minutes of running a week, unless Dr Fitzpatrick refers to virtual runners and footballers, in other words, videogamers. Dr Fitzpatrick may be relieved to know that moderate activity may include walking, gardening, housework, and sex. Even Dr Fitzpatrick admits knowing that self-reporting is heinously inaccurate, so his daft bias survey carries no significance and should not grace these pages.

3. No advocate of physical activity has ever claimed that a GP can transform all couch potatoes into athletes. However, there is evidence that even brief consultations lasting a few minutes or simple pedometer-based programmes delivered through health professionals can lead to substantial increases in patients' activity levels (by $\sim 30 \%$ ). ${ }^{7}$ It stands to reason that any intervention can be more effectively implemented when healthcare professionals are sufficiently educated and trained to deliver it to their patients.

\section{Richard Weiler,}

Honorary Consultant in Sport and Exercise Medicine, GP, University College London

Hospitals NHS Foundation Trust, 235

Euston Road, London, NW1 2BU.

E-mail: rweileradoctors.org.uk

Emmanuel Stamatakis,

Senior Research Associate/NIHR Career Development Fellow, University College London.

\section{Steven N Blair,}

Professor, Faculty Affiliate, Division of Health Aspects of Physical Activity/EPID, University of South Carolina, Department of Exercise Science, Columbia, South Carolina, US

\section{REFERENCES}

1. Fitzpatrick M. The Olympic legacy. Br J Gen Pract 2011; 61(592): 688.

2. Fitzpatrick M. Olympic absurdities. Br J Gen Pract 2012; 62(594): 13.

2. Garry JP, Diamond JJ, Whitley TW. Physical activity curricula in medical schools. Acad Med 2002; 77(8): 818-820.

3. Chew S, Weiler R, Coombs N, et al. Physical Activity Teaching within the Curricula of the 33 United Kingdom Medical Schools. [Poster presentation]. London: UCL Physical Activity Research Group Symposium, November 28th 2011.

4. World Health Organization. Global recommendations on physical activity for health. Geneva: WHO, 2010. http://uww.who.int/dietphysicalactivity/strategy/eb11 344/strategy_english_web.pdf laccessed 10 Jan 2012)

5. Department of Health. Start active, stay active: a report on physical activity from the four home countries. London: DoH, 2011. http://www.dh.gov.uk/en/Publicationsandstatistics/P ublications/PublicationsPolicyAndGuidance/DH_128 209 (accessed 10 Jan 2012).

6. Marcus BH, Williams DM, Dubbert PM, et al. Physical activity intervention studies: what we know and what we need to know: a scientific statement from the American Heart Association Council on Nutrition, Physical Activity, and Metabolism (Subcommittee on Physical Activity); Council on Cardiovascular Disease in the Young; and the Interdisciplinary Working Group on Quality of Care and Outcomes Research. Circulation 2006; 114(24): 2739-2752.

\section{Medical \\ professionalism and pay-for-performance}

In his Editor's Briefing, Roger Jones opines that the Quality and Outcomes Framework may lead to maladaptive behaviours and deprofessionalisation. ${ }^{1}$ This begs the question, what exactly constitutes medical professionalism? In 1977, Dr CF Donovan defined clinical competence as the first key responsibility of the doctor. ${ }^{2}$ A continuing commitment to excellence through the application of current knowledge, and the continuing acquisition of new knowledge are key attributes of medical professionalism. ${ }^{3}$ However, the population mortality reduction of 11 lives per 100000 people as a consequence of the pay-for-performance contract in England, and the implication that a similar payment system improved blood pressure control in Scotland, suggests that the ethos of professionalism may not be centre stage in medical education. ${ }^{4,5}$ Success for the profession will arrive when there is no difference between measured patient outcomes, irrespective of the means of doctor remuneration.

Jacqueline PM Chambers,

GP, The Surgery, 167 Glasnevin Avenue,

Dublin 11, Ireland.

E-mail:jpmchambersaeircom.net

William Tormey,

GP, The Surgery, Dublin.

\section{REFERENCES}

1. Jones R. Editor's briefing. Br J Gen Pract 2011; 61(588): 427.

2. Donovan CF. A doctor's responsibility to his patients. Proc R Soc Med 1977; 70(1): 21-23.

3. Swick HM. Toward a normative definition of medical professionalism. Acad Med 2000; 75(6): 612-616.

4. Fleetcroft R, Parekh-Bhurke S, Howe A, et al. The UK pay-for-performance programme in primary care: estimation of population mortality reduction. Br J Gen Pract 2010; DOI: 10.3399/bjgp10X515359.

5. Simpson CR, Hannaford PC, Ritchie LD, et al. Impact of the pay-for-performance contract and the management of hypertension in Scottish primary care: a 6-year population based repeated crosssectional study. Br J Gen Pract 2011; DOI: 10.3399/bjgp11X583407.

Published online first 19 August 2011 DOI: 10.3399/bjgp11X595675 